\title{
The effect of psychopathology on set shifting and reversal learning in schizophrenia
}

\author{
Eirini Theochari ${ }^{1}$, Dimitrios Kontis ${ }^{*}$, Spiros Kleisas ${ }^{1}$, Stamatina Kalogerakou ${ }^{2}$, Angeliki Andreopoulou², \\ Charalambos Karouzos ${ }^{1}$, Eleftheria Tsaltas ${ }^{2}$ \\ From $1^{\text {st }}$ International Congress on Neurobiology and Clinical Psychopharmacology and European \\ Psychiatric Association Conference on Treatment Guidance \\ Thessaloniki, Greece. 19-22 November 2009
}

\section{Background}

Recent studies suggest that negative and disorganized symptoms of schizophrenia are modestly associated with cognitive deficits, whereas positive and depressive symptoms are not.

\section{Materials and methods}

27 patients with schizophrenia were tested on an intradimensional/extra-dimensional set-shifting (IEDS) task of the Cambridge Neuropsychological Test Automated Battery (CANTAB) in an acute psychiatric ward. Their psychopathological state was assessed with PANSS and the Calgary Depression Scale. Correlation analysis was used to examine the association of psychopathology with set shifting and reversal learning performance.

\section{Results}

We found significant positive correlations of PANSS total (rho $=0.53, \mathrm{p}=0.016)$ and general $(\mathrm{rho}=0.590, \mathrm{p}$ $=0.006)$ scores with the intra-dimensional reversal errors in IEDS. No significant correlations of IEDS performance variables with the PANSS positive or negative symptoms scores were found. PANSS disorganization scores showed positive correlations with intra-dimensional reversal errors $(\mathrm{rho}=0.639, \mathrm{p}=0.002)$, but a small negative correlation with the number of completed IEDS stages ( $r$ o $=-0.392, \mathrm{p}=0.043$ ). No association was detected between depressive symptoms and IEDS task performance.

\section{Conclusions}

We found modest associations between symptomatology and the intra-dimensional reversal ability in

\footnotetext{
${ }^{1}$ 1st Psychiatric Department, Psychiatric Hospital of Attica, Athens, Greece
}

schizophrenia. These associations are mainly driven by disorganization symptoms. Positive, negative and depressive symptoms are not associated with IEDS performance.

\section{Author details}

${ }^{1} 1$ st Psychiatric Department, Psychiatric Hospital of Attica, Athens, Greece. ${ }^{2}$ Experimental Psychology Laboratory, Department of Psychiatry, Eginition Hospital, Athens University Medical School, Athens, Greece.

Published: 22 April 2010

\section{References}

1. Dominguez Mde G, Viechtbauer W, Simons CJ, van Os J, Krabbendam L: Are psychotic psychopathology and neurocognition orthogonal? A systematic review of their associations. Psychol Bull 2009, 135(1):157-71.

2. McKirdy J, Sussmann JE, Hall J, Lawrie SM, Johnstone EC, McIntosh AM: Set shifting and reversal learning in patients with bipolar disorder or schizophrenia. Psychol Med 2009, 39(8):1289-93.

doi:10.1186/1744-859X-9-S1-S126

Cite this article as: Theochari et al:: The effect of psychopathology on set shifting and reversal learning in schizophrenia. Annals of General Psychiatry 2010 9(Suppl 1):S126.

Submit your next manuscript to BioMed Central and take full advantage of:

- Convenient online submission

- Thorough peer review

- No space constraints or color figure charges

- Immediate publication on acceptance

- Inclusion in PubIMed, CAS, Scopus and Google Scholar

- Research which is freely available for redistribution 